\title{
Application of Soil Water Index to landslide prediction in snowy regions: sensitivity analysis in Japan and preliminary results from Tomsk, Russia
}

\author{
Hiroshi Matsuyama ${ }^{1 *}$ (D) Hitoshi Saito ${ }^{2}$ and Valerii Zemtsov ${ }^{3}$
}

\begin{abstract}
Soil Water Index (SWI) represents the conceptual water stored in the soil and is calculated using a three-layer tank model with hourly precipitation. In Japan, landslide disasters are likely to occur when SWI in an event exceeds the maximum value of the past 10 years; however, snowmelt-driven landslide disasters have not been considered yet. Using the tank model that simultaneously calculates SWI and runoff, we implemented the snowfall-accumulationsnowmelt processes into the original SWI and applied the modified SWI to meteorological data in Tomsk, Russia, in spring 2010 when severe flood and landslide disasters had occurred. We conducted a sensitivity analysis of hourly precipitation in snowy region in Japan considering that meteorological data in Russia are available every $3 \mathrm{~h}$. When we input the average of the three-hourly accumulated precipitation to calculate SWI, the result was almost identical to that of the observed hourly precipitation being given. We then estimated the hourly temperature by linearly interpolating the data every $3 \mathrm{~h}$, and set the threshold of liquid/solid precipitation. The degree-hour method was employed to calculate the snowmelt. The modified SWI predicted the occurrence of snowmelt-driven landslide disasters in Japan when the calculated SWI exceeded the maximum value in the snowmelt season (March-May) for the past 10 years. When applied to meteorological data in Tomsk, the modified SWI and calculated runoff captured the timing of snowmelt-driven flood and landslide disasters in spring 2010. We demonstrated that by focusing on the maximum value of SWI in the snowmelt season for the past 10 years, we can predict snowmelt-driven landslide disasters.
\end{abstract}

Keywords: Soil Water Index (SWI), Landslide prediction, Snowmelt-driven landslide disaster, Hourly precipitation, Tomsk

\section{Introduction}

Soil Water Index (SWI) represents conceptual water stored in the soil and is calculated using a three-layer tank model with hourly precipitation (Okada et al. 2001). SWI is the sum of the water $S_{1}+S_{2}+S_{3}$ in Fig. 1 (unit: $\mathrm{mm}$, see the next section). Considering that all precipitation does not immediately drain out but is stored in the soil for a long time, SWI is regarded as an

\footnotetext{
* Correspondence: matuyama@tmu.ac.jp

'Department of Geography, Tokyo Metropolitan University, 1-1

Minami-Osawa, Hachioji, Tokyo 192-0397, Japan

Full list of author information is available at the end of the article
}

index of long-term precipitation for landslide disaster assessment (Okada et al. 2001).

Many studies have focused on quantifying rainfall characteristics such as the minimum rainfall intensity, total rainfall, and SWI at which landslide disasters have reportedly occurred in order to derive empirically critical thresholds for landslide disaster assessment (Guzzetti et al. 2008; Saito et al. 2010a; Chen et al. 2017). The simplicity of this approach offers a straightforward means for issuing regional-scale meteorological disaster on the basis of rainfall data. In Japan, SWI and $60 \mathrm{~min}$ accumulated precipitation are simultaneously used as nationwide early warning system for landslide disasters 


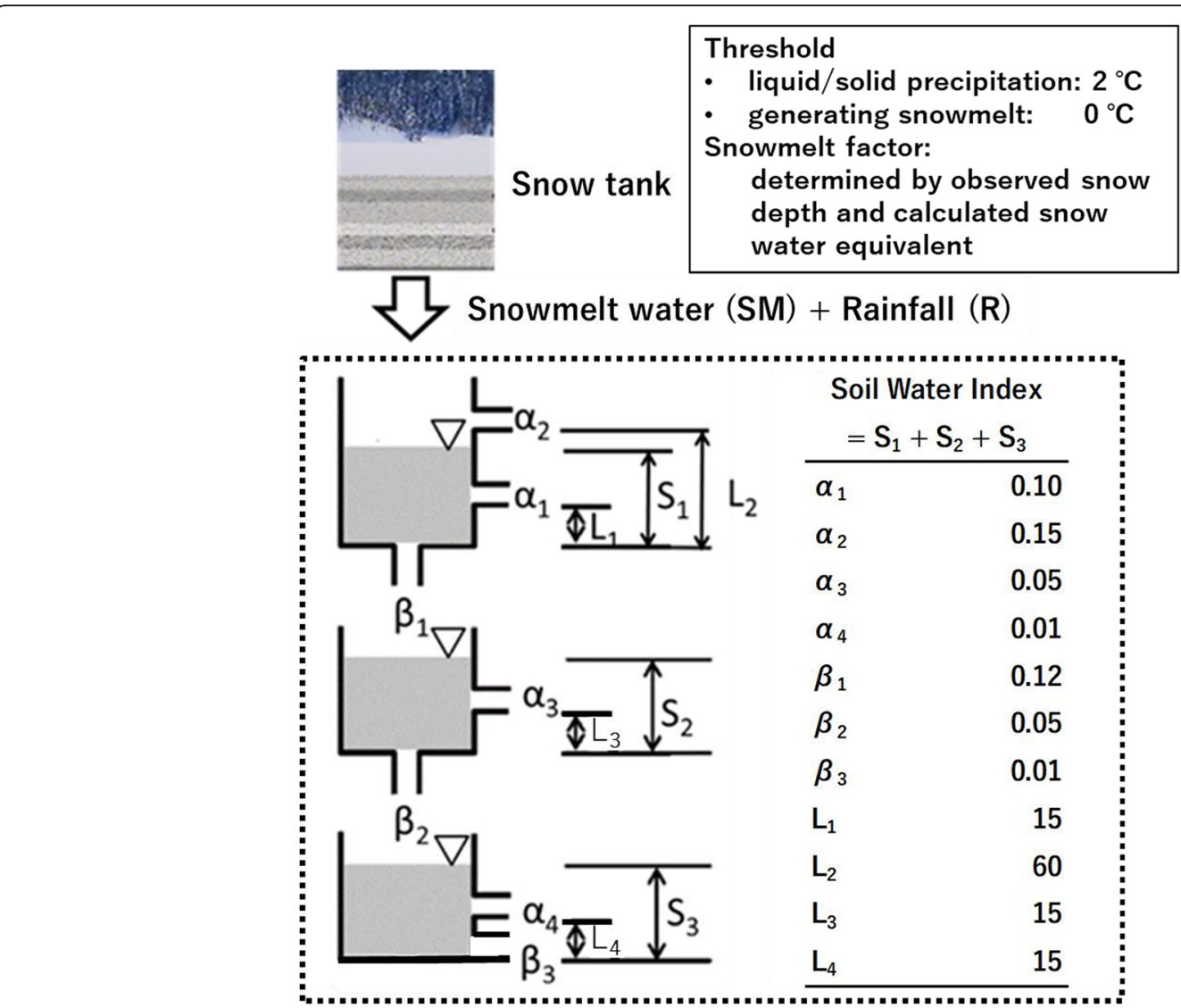

Fig. 1 Schematic diagram of the three-layer tank model plus snow tank, modified after Shimizu and Uemura (2018). The figures and table within the dotted box represent original SWI (Okada et al. 2001). $a_{1-4}$ and $\beta_{1-3}$ are dimensionless while $L_{1-4}$ and $S_{1-3}$ have unit of mm. The parameters related to snow are shown in the solid box

(Osanai et al. 2010). However, it has also been demonstrated that landslide disasters are likely to occur when SWI of an event exceeds the maximum value of the past 10 years (Okada et al. 2001; Okada 2007). Thus, we can assess landslide disasters by using SWI alone. From this viewpoint, we have studied SWI and empirically proved its validity (Saito et al. 2010a, b, 2011; Saito and Matsuyama 2012, 2015).

However, the problem with SWI is that percolation of precipitation into soil in winter is not considered (Usutani et al. 2013; Nakatsugawa et al. 2015; Miyazaki et al. 2017; Siva Subramanian et al. 2018). Landslide disasters are common during heavy rainfall events. Torrential rains supply water into soil surface rapidly and drastically, whereas snowmelt hydrates the soil surface continuously. We have to consider this kind of difference in water load to surface soil layer. Accordingly, landslide disasters can occur in snowy regions even during fine weather in the snowmelt season (Usutani et al. 2013; Nakatsugawa et al. 2015; Miyazaki et al. 2017; Siva Subramanian et al. 2018).
Usutani et al. (2013) investigated the landslide disaster that occurred at Nakayama pass near Sapporo, northern Japan, on May 4, 2012 (Fig. 2b). They demonstrated the possibility of increasing soil moisture due to snowmelt without precipitation during the landslide event. This is obvious; however, the effect is not implemented in hydrological modeling. The hydrological model used in their study was optimized to the basin they analyzed and cannot be applied to other basins in its present form. Nakatsugawa et al. (2015) and Miyazaki et al. (2017) investigated the same landslide disaster at Nakayama pass using SWI. They prepared mesh data and solved the surface energy balance for calculating snowmelt. This is essentially correct; however, several data are necessary for estimating snowmelt, i.e., temperature, relative humidity, wind speed, snow depth, short wave downward radiation, and air pressure (all of the hourly data), along with topography and land cover at each mesh. Siva Subramanian et al. (2018) also analyzed the same landslide disaster at Nakayama pass with the use of SWI and hourly precipitation. As will be explained in Section 3.2 


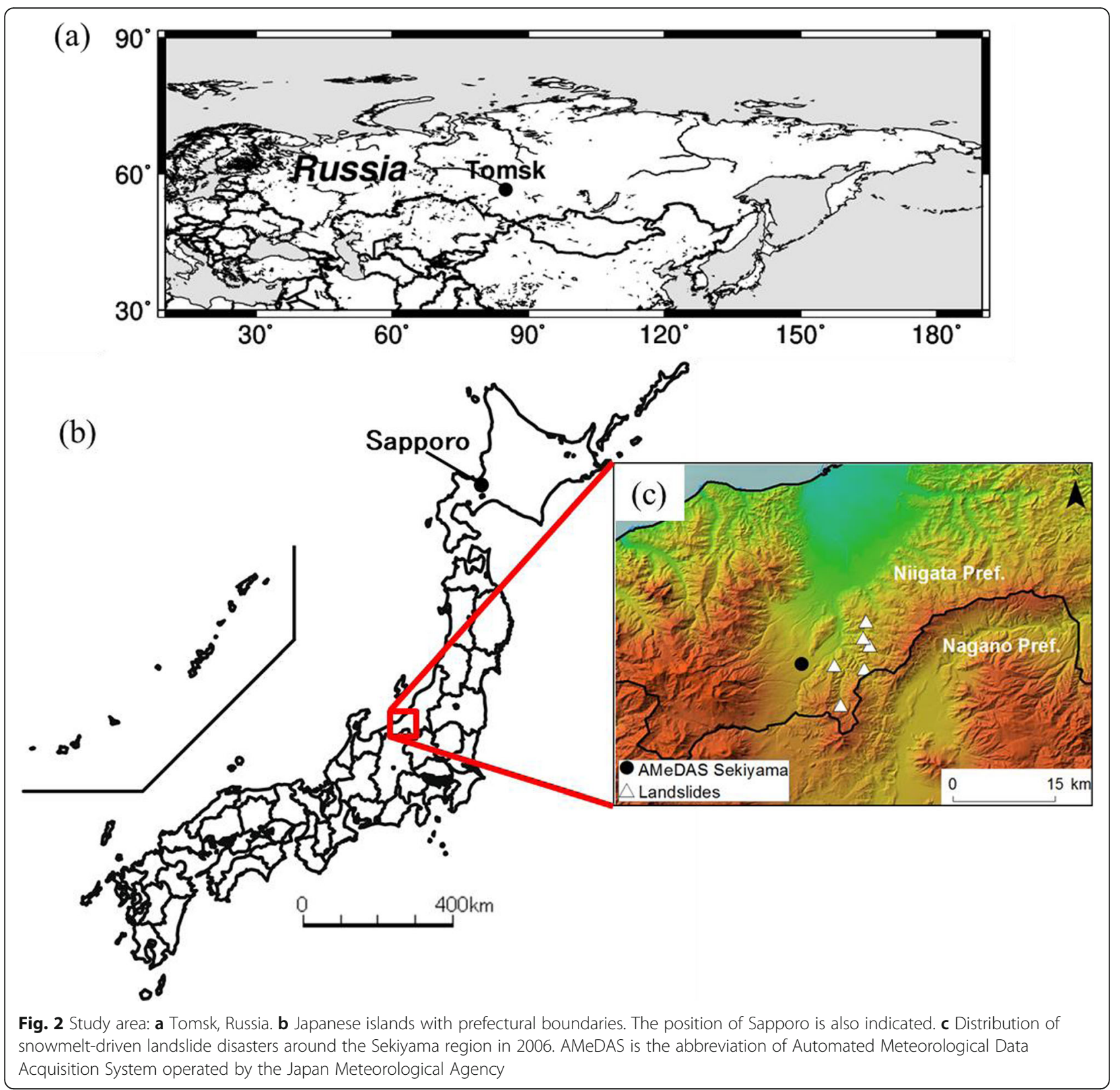

of the present study, we can only use three-hourly precipitation and temperature, so that we cannot adopt the method of Siva Subramanian et al. (2018). A simpler method for predicting snowmelt-driven landslide disasters is required.

Under the framework of Japan-Russia collaborative research programs, the authors have pursued the possibility of applying SWI to predict snowmelt-driven landslide and flood disasters around Tomsk, Russia (Fig. 2a). At Tomsk, snowmelt-driven landslide and flood disasters sometimes occur on the steep slopes of the Tom valley and valleys of its small tributaries. Researchers at the National Research Tomsk State University have monitored snowmelt- driven landslide and flood disasters and their prediction with the aid of local governments. The application of SWI to their studies enables the prediction and prevention of natural hazards, which is vital for the lives of residents in Tomsk.

In this respect, the three-layer tank model simultaneously calculates SWI and runoff (Fig. 1). Usually, when SWI is large, runoff is also expected to be large. Based on these characteristics, Japan Meteorological Agency predicts floods of rivers by using runoff calculated by the three-layer tank model (Fig. 1, Tanaka et al. 2008; Ohta and Makihara 2019). It is spatially integrated at a certain point above the basin. However, snowmelt water is not considered in this calculation either (Tanaka et al. 2008). 
Considering these problems, the objective of this study is to develop a simpler method with SWI for predicting regional-scale snowmelt-driven landslide and flood disasters in Tomsk, Russia. In Tomsk, we can only use three-hourly meteorological data (RIHMI-WDC 2020, see Section 3.2). In such situations, we would like to predict the occurrence of snowmelt-driven landslide and flood disasters properly because they sometimes occur there (Fig. 3). In order to apply SWI and runoff in the snowmelt season, we implemented snowfall-accumulationsnowmelt processes into the original SWI (see next section). The precise procedures are as follows.

1) For snowy regions in Japan where information on snowmelt-driven landslide disasters is available (location and date of occurrence), we clarified the change in SWI when hourly precipitation was estimated from three-hourly accumulated precipitation (see Section 4.1).

2) In the same snowy region in Japan, we implemented snowfall-accumulation-snowmelt processes into the original SWI (Fig. 1, see Section 4.2).
3) Based on the results of (1) and (2), we calculated SWI and runoff at Tomsk based on the threehourly meteorological data. In the spring of 2010 , when severe snowmelt-driven floods occurred in Tomsk (Fig. 3), landslides were observed as well. We then evaluated the calculated SWI and runoff during that event.

\section{Structure of the original SWI and modified SWI}

The original SWI is calculated by the three-layer tank model (dashed line within Fig. 1, Okada et al. 2001). The units of variables and parameters that appear in the following equations are given in the caption of Fig. 1. In this figure, first tank, second tank, and third tank are arranged from the top within the dashed line. Runoff from the respective tank corresponds to surface runoff $\left(Q_{1}\right)$, intermediate runoff $\left(\mathrm{Q}_{2}\right)$, and base runoff $\left(\mathrm{Q}_{3}\right)$. They are calculated as follows unless brace \{\} is negative (Fig. 1).

$$
\begin{aligned}
& \mathrm{Q}_{1}(\mathrm{t})=\alpha_{1}\left\{\mathrm{~S}_{1}(\mathrm{t})-\mathrm{L}_{1}\right\}+\alpha_{2}\left\{\mathrm{~S}_{1}(\mathrm{t})-\mathrm{L}_{2}\right\} \\
& \mathrm{Q}_{2}(\mathrm{t})=\alpha_{3}\left\{\mathrm{~S}_{2}(\mathrm{t})-\mathrm{L}_{3}\right\}
\end{aligned}
$$

(a)

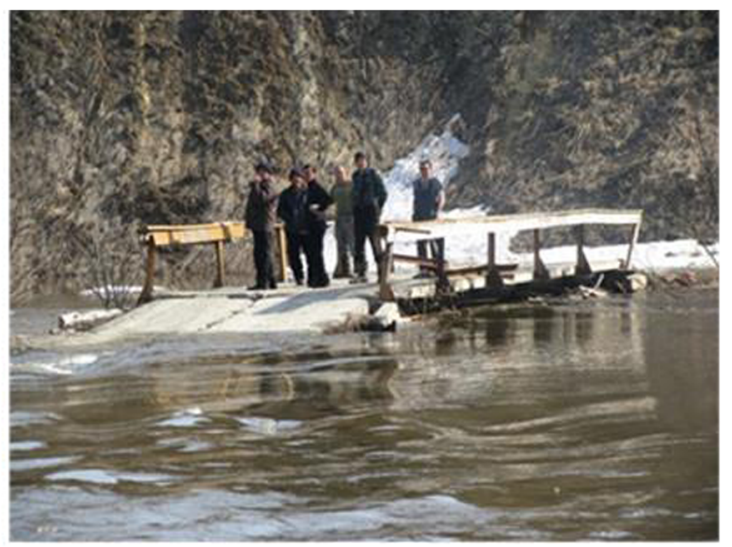

(c)

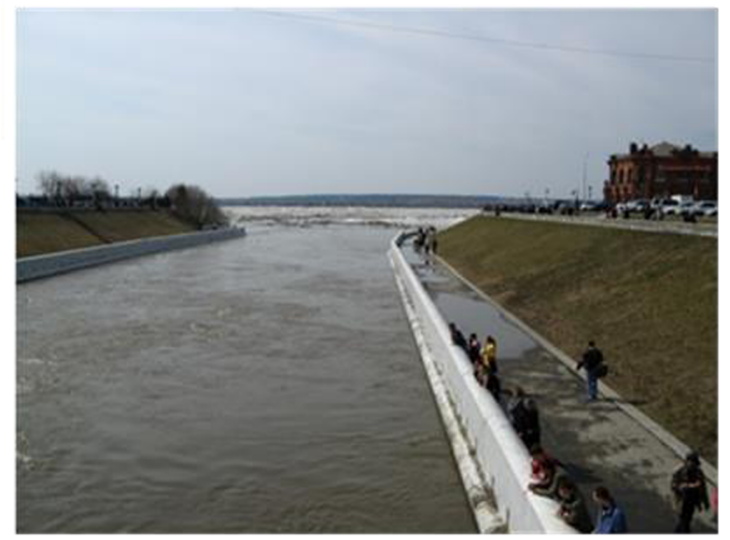

(b)

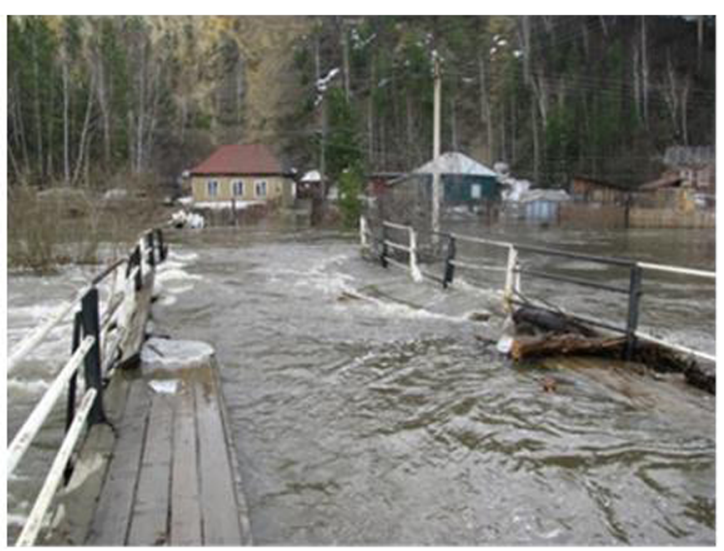

(d)

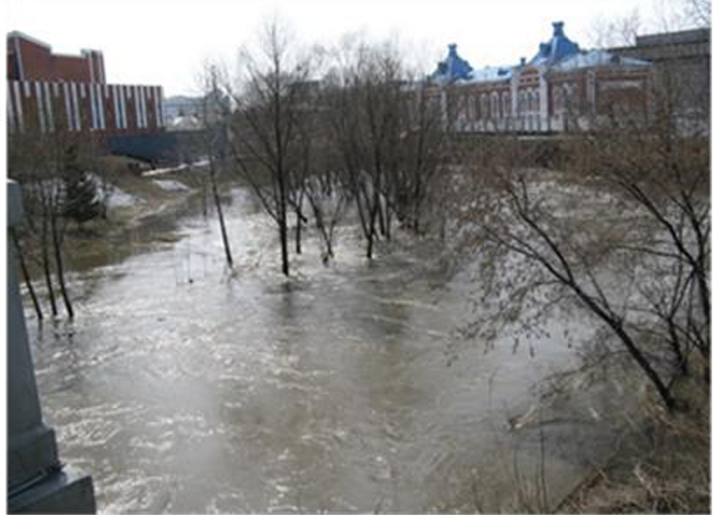

Fig. 3 Snowmelt-driven flood disasters in Tomsk neighborhoods at the end of April 2010. a, b April 28, 2010; c, d April 30, 2010 (Territorial Center "Tomskgeomonitoring" 2020) 


$$
\mathrm{Q}_{3}(\mathrm{t})=\beta_{3} \times \mathrm{S}_{3}(\mathrm{t})+\alpha_{4}\left\{\mathrm{~S}_{3}(\mathrm{t})-\mathrm{L}_{4}\right\} .
$$

Because impermeable layer is supposed to be located under the third tank, percolation from the third tank (first term of the right-hand side of Eq. 3) is included in the base runoff (Okada 2020, personal communication).

$\mathrm{S}_{1}(\mathrm{t}), \mathrm{S}_{2}(\mathrm{t})$, and $\mathrm{S}_{3}(\mathrm{t})$ are calculated as follows. $\Delta \mathrm{t}$ is 20 min where hourly precipitation is divided by three and given to the calculation (Okada et al. 2001).

$$
\begin{aligned}
& \mathrm{S}_{1}(t+\Delta \mathrm{t})=\mathrm{S}_{1}(\mathrm{t})-\left\{\mathrm{Q}_{1}(\mathrm{t})+\mathrm{Z}_{1}(\mathrm{t})\right\}+\mathrm{R}(\Delta \mathrm{t}), \\
& \mathrm{S}_{2}(t+\Delta \mathrm{t})=\mathrm{S}_{2}(\mathrm{t})-\left\{\mathrm{Q}_{2}(\mathrm{t})+\mathrm{Z}_{2}(\mathrm{t})\right\}+\mathrm{Z}_{1}(\Delta \mathrm{t}), \\
& \mathrm{S}_{3}(t+\Delta \mathrm{t})=\mathrm{S}_{3}(\mathrm{t})-\mathrm{Q}_{3}(\mathrm{t})+\mathrm{Z}_{2}(\Delta \mathrm{t}),
\end{aligned}
$$

where $Z_{1}(t)$ and $Z_{2}(t)$ are vertical percolation. $R(\Delta t)$ is rainfall.

$$
\begin{aligned}
& \mathrm{Z}_{1}(\mathrm{t})=\beta_{1} \times \mathrm{S}_{1}(\mathrm{t}), \\
& \mathrm{Z}_{2}(\mathrm{t})=\beta_{2} \times \mathrm{S}_{2}(\mathrm{t}), \\
& \mathrm{SWI}(\mathrm{t})=\mathrm{S}_{1}(\mathrm{t})+\mathrm{S}_{2}(\mathrm{t})+\mathrm{S}_{3}(\mathrm{t}) .
\end{aligned}
$$

The parameters in Eqs. (1), (2), (3), (4), (5), (6), (7), and (8) are tabulated in Fig. 1. They were optimized for granite soil in Japan (Ishihara and Kobatake 1979); however, these parameters are applicable all over the world because SWI uses relative ranks of past records at the site and compares them with the rank of SWI at the time of interest. Although different parameters modulate the absolute SWI value, differences of soil type, geology, and geomorphology rarely affect the relative ranks of SWI (Okada et al. 2001). For the same reason, we do not take into account the difference of climate, especially snow, in Japan and Russia.

In the calculation of the original SWI mentioned above, snowfall is treated as rainfall, and is input in Eq. (4) even in winter (Okada et al. 2001). This is an apparent contradiction, so that we separated snowfall and rainfall in this study and implemented snowfallaccumulation-snowmelt processes into the original SWI (Fig. 1).

Precipitation was discriminated to rainfall and snowfall. Following Ogawa and Nogami (1994), we set the threshold of liquid/solid precipitation to $2{ }^{\circ} \mathrm{C}$. We assumed that snowmelt $(\mathrm{SM})$ occurred when the temperature was greater than $0{ }^{\circ} \mathrm{C}$ and calculated it using the degree-hour method (for example, Yamazaki 1994).

$$
\operatorname{SM}(t)=\text { snowmelt factor } \times T(t),
$$

where $\operatorname{SM}(\mathrm{t})$ is snowmelt water $(\mathrm{mm} / \mathrm{h})$. Snowmelt factor is a constant that has the unit of $\mathrm{mm} /\left(\mathrm{h} \cdot{ }^{\circ} \mathrm{C}\right)$, and $\mathrm{T}(\mathrm{t})$ is hourly temperature $\left({ }^{\circ} \mathrm{C}\right)$. We determined the snowmelt factor by trial and error, not distinguishing the snowmelt between snow surface and atmosphere and that between snow and land surface. Specifically, we only modified the snowmelt factor by matching the appearance/disappearance of the observed snow depth and calculated snow water equivalent. We determined the snowmelt factor by visual inspection of the time series of the observed snow depth and calculated snow water equivalent from October to the next September.

Without the presence of snow, $\mathrm{SM}(\mathrm{t})$ is $0(\mathrm{~mm} / \mathrm{h})$. In this case, the behavior of the modified SWI is same as the original SWI, i.e., they are identical in the warm season.

\section{Study areas and data used}

\subsection{Sekiyama region and data in Japan}

We selected Sekiyama region in Niigata Prefecture for the study area (Fig. 2c) because the area is a snowy region and characterized by frequent snowmelt-driven landslide disasters (e.g., Kimura et al. 2014). We obtained information on the location and date of the occurrence of snowmelt-driven landslide disasters from the Ministry of Land, Infrastructure and Transport and related websites. We can use the data of the snowmelt season in 2006, and the temporal resolution is 1 day. The landslides treated here is a deep-seated rotational landslide (Cruden and Varnes 1996). SWI is also validated for prediction of deep-seated rotational landslides and has a high correlation with movement of these landslides (e.g., Sekine and Katsura 2020).

The landslides that occurred at the mountainous area (Fig. 2c) are characterized by sedimentary rocks. At AMeDAS Sekiyama (Automated Meteorological Data Acquisition System, Japan Meteorological Agency 2020, Fig. 2c), annual mean precipitation and temperature from 1981 to 2010 are $2013.4 \mathrm{~mm}$ and $11.7^{\circ} \mathrm{C}$, respectively (Japan Meteorological Agency 2020). From December to the next March, monthly mean temperature is below $0{ }^{\circ} \mathrm{C}$. Because Sekiyama is faced to Japan Sea side, much snow is observed in winter, i.e., total precipitation from December to the next March is $723.8 \mathrm{~mm}$. Usually, snow is accumulated from November to the next April; however, in some years, it is also found in May. The maximum snow depth is more than $2 \mathrm{~m}$ in February. The seasonal march of the climate elements at Sekiyama will be later displayed in Fig. 5.

We can use hourly meteorological data at AMeDAS Sekiyama for precipitation, temperature, snow depth, snowfall, wind direction/speed, and sunshine duration data after April 1976. The temporal resolution is $1 \mathrm{~h}$. Among them, we used hourly precipitation and temperature for calculation, and snow depth for validation. Because Okada et al. (2001) and Okada (2007) demonstrated that landslide disasters are likely to occur when SWI of an event is larger than the maximum SWI of the past 10 years, the reference period was from January 1995 to December 2004, and the validation period was from January 2005 to 
December 2006 when information on snowmelt-driven landslide disasters is available.

Using wind speed, we could correct the undercatch of the snowfall into rain gauge (Motoyama 1990; Ohno et al. 1998); however, the final objective of this study is to apply SWI to Tomsk where we can only use three-hourly precipitation and temperature, and the snow depth of every 5 or 10 days (see next section). Because the temporal resolution of snow depth measurement is too coarse in Tomsk, we did not consider the undercatch of solid precipitation.

\subsection{Tomsk and data in Russia}

Tomsk is located in Western Siberia (Fig. 2a), and it is one of the old cities in Siberia. Tomsk is faced with Tom River, a tributary of Ob River. At the base of the slope of Tom River and its tributaries, there are impermeable layers (sandstones, argillaceous shales, clays), sandy layers containing underground water horizons, and layered strata of loose sandy-argillaceous deposits that lie on them. Landslides near Tomsk are common along high and steep slopes of the Tom river valley and valleys of its tributaries.

Because Tomsk is located inland of the Eurasian continent, it is relatively hot in summer and cold in winter. The annual mean temperature from 1981 to 2010 is $0.9^{\circ} \mathrm{C}$, while mean temperature in January and July is $17.1^{\circ} \mathrm{C}$ and $18.7^{\circ} \mathrm{C}$, respectively (RIHMI-WDC 2020). The annual mean precipitation from 1981 to 2010 is $566.5 \mathrm{~mm}$. Monthly mean temperature from November to the next March is below $0{ }^{\circ} \mathrm{C}$, and snow is usually accumulated from October to April. From November to March, the total precipitation is $185.0 \mathrm{~mm}$.

We archived hydrometeorological data in Tomsk from RIHMI-WDC (2020). Both daily and three-hourly data are available, and we used the latter beginning on January 1, 1966. Although not described in detail here, we can use routine meteorological observations. Among them, we used three-hourly precipitation and temperature for calculating SWI.

For validation, we used snow depth data which are available every 5 or 10 days during the snow season (10th, 20th, and the end of month. In some months/ years, 5th, 15th, and 25th are added). Occasionally, we could not clearly determine the disappearance date of snow with the use of these data alone. At Tomsk, the reference period was from January 1999 to December 2008, and the validation period was from January 2009 to December 2010 because snowmelt-driven flood and landslide disasters occurred in the spring of 2010.

\section{Methods}

\subsection{Sensitivity analysis of SWI on the characteristics of} hourly precipitation

By using hourly precipitation at AMeDAS Sekiyama (Fig. $2 \mathrm{c}$ ), we calculated three-hourly accumulated precipitation from 1995 to 2006. We then assigned the average of threehourly accumulated precipitation to the hourly data. Next, we calculated SWI at AMeDAS Sekiyama using (1) observed hourly precipitation and (2) estimated hourly precipitation mentioned above, and then compared them. We performed the calculation from January 1995 to December 2006. Here, we only verified the sensitivity of the characteristics of hourly precipitation given to calculate SWI; as such, we did not implement snowfallaccumulation-snowmelt processes in this stage.

\subsection{Implementation of snowfall-accumulation-snowmelt processes into the original SWI}

Next, we implemented snowfall-accumulation-snowmelt processes into the original SWI (Fig. 1) to reproduce the occurrence of snowmelt-driven landslide disasters. We estimated the hourly temperature by linearly interpolating the data every $3 \mathrm{~h}$. We also provided hourly precipitation as the average of the three-hourly accumulated precipitation. Based on the explanation in Section 2, we determined the snowmelt factor at Sekiyama from October 1, 2005 to September 30, 2006. It was estimated as $1.3 \mathrm{~mm} \cdot{ }^{\circ} \mathrm{C} /$ day, which was divided by 24 for giving the degree-hour method (Eq. 10). We then performed the calculation from January 1995 to December 2006 by fixing the snowmelt factor.

In this study, we calculated SWI and compared it not only with the maximum value of the past 10 years for the whole year but also with that of the snowmelt season. Here, we defined the snowmelt season from March to May, considering the presence of snow in both Sekiyama and Tomsk.

\subsection{Application of modified SWI to meteorological data in Tomsk}

We applied the modified SWI, in which snowfallaccumulation-snowmelt processes were implemented, to the meteorological data in Tomsk. We investigated whether we could reproduce the situation at Tomsk in the spring of 2010 when snowmelt-driven flood and landslide disasters had occurred (Fig. 3). We determined the snowmelt factor in Tomsk by using data from October 1, 2009 to September 30, 2010, following the method explained in Section 2. In this case, the snowmelt factor was determined as $0.7 \mathrm{~mm} \cdot{ }^{\circ} \mathrm{C} /$ day which was divided by 24 for giving the degree-hour method (Eq. 10). We performed the calculation from January 1999 to December 2010 by fixing the snowmelt factor.

\section{Results}

5.1 Sensitivity analysis of SWI on the characteristics of hourly precipitation

Figure 4a displays SWI (orange line) calculated by the observed hourly precipitation (blue bars) at AMeDAS 


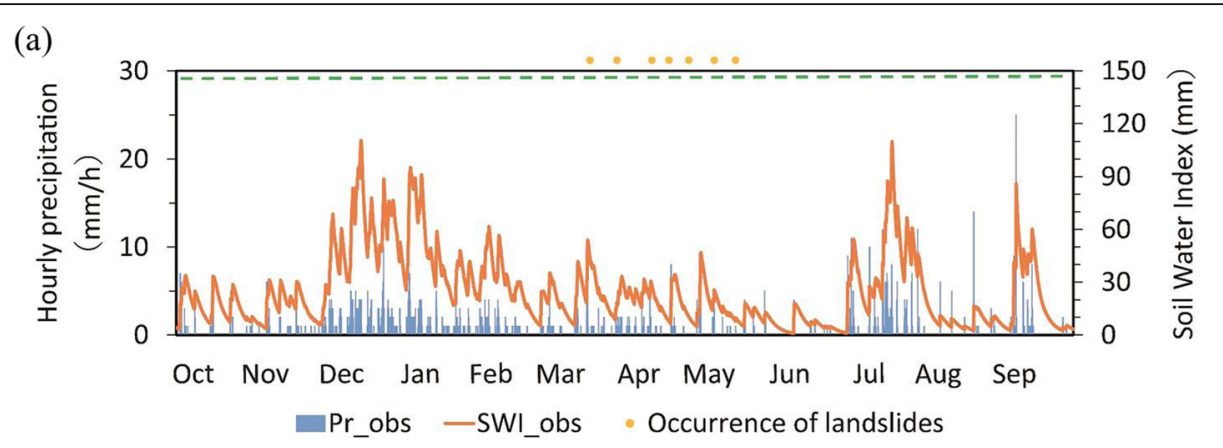

(b)
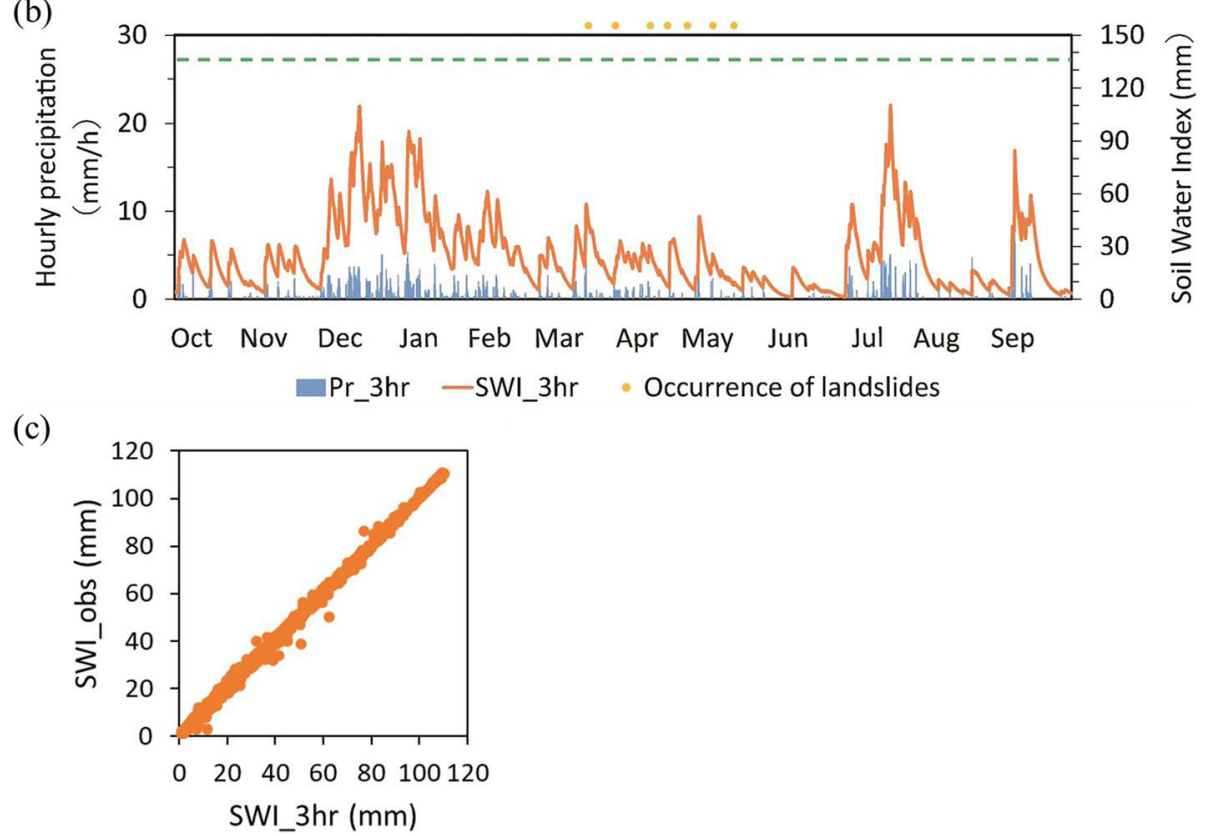

Fig. 4 a Original SWI (orange line) calculated by observed hourly precipitation (blue bars) at AMeDAS Sekiyama (Fig. 2c) from October 1, 2005, to September 30, 2006. Yellow dots represent the occurrences of snowmelt-driven landslide disasters. The maximum SWI (143 mm) of the past 10 years (1995-2004) is depicted by the green dashed line. In this figure, snowfall-accumulation-snowmelt processes are not implemented. b Same as $\mathbf{a}$ but the hourly precipitation is given as the average of three-hourly accumulated precipitation. In this case, the maximum SWI of the past 10 years is $135 \mathrm{~mm}$. c Scatter diagram between SWI_3hr (b) and SWI_obs (a), with the correlation coefficient being nearly equal to 1

Sekiyama from October 1, 2005 to September 30, 2006. In this figure, snowfall-accumulation-snowmelt processes were not implemented; therefore, SWI increased in the winter of 2005 and summer of 2006 when larger precipitation was observed. It is possible that precipitation in the winter of 2005 occurred as snowfall; however, this was treated as rainfall for this calculation because percolation into soil occurred even with snowfall. In the upper part of Fig. $4 \mathrm{a}$, the occurrences of landslide disasters are plotted as yellow dots. In this figure, SWI does not show any increase in the spring of 2006 when snowmelt-driven landslide disasters actually occurred. The maximum SWI from October 2005 to September 2006 is 111 $\mathrm{mm}$ on December 15, 2005. Since the maximum SWI in the past 10 years is $143 \mathrm{~mm}$ (green dashed line in Fig. 4a), SWI on December 15, 2005, was not sufficient to generate landslide disasters.

Figure $4 \mathrm{~b}$ is the same as Fig. 4a, but the average of the three-hourly accumulated precipitation was used in the calculation of SWI. The difference in hourly precipitation is apparent in Fig. 4a and b; that is, larger hourly precipitation is observed in Fig. 4a, whereas such large precipitation is averaged in Fig. 4b. One surprising fact is that we do not recognize large differences in the time series of SWI in Fig. 4a and b. In Fig. 4b, the maximum SWI from October 2005 to September 2006 is 110 $\mathrm{mm}$ on December 15, 2005, which is almost identical to Fig. 4a. In this case, the maximum SWI in the past 10 years was $135 \mathrm{~mm}$ (green dashed line in Fig. 4b). 
Figure 4c displays a scatter diagram of SWI calculated by the observed hourly precipitation (Fig. 4a) and estimated hourly precipitation (Fig. 4b). The scatters are distributed along the 1:1 line, with the correlation coefficient being nearly equal to 1 . We verified that estimating hourly precipitation as the average of threehourly accumulated precipitation has almost no effect on the calculation of SWI, that is, three-hourly data are sufficient.

Because three-hourly accumulated precipitation is same as for both calculations, we think the difference of SWI is forced by the precipitation, and basically the difference appears within $3 \mathrm{~h}$. A delay of response in SWI for precipitation input may contribute to the difference; however, such effect is subtle as shown in Fig. 4. Based on this result, we implemented the snowfall-accumulationsnowmelt processes into the original SWI (Fig. 1).

\subsection{Implementation of snowfall-accumulation-snowmelt processes into the original SWI}

Figure 5a displays SWI calculated by the estimated hourly precipitation (average of three-hourly accumulated precipitation) at AMeDAS Sekiyama from October 2005 to September 2006. In this calculation, snowfallaccumulation-snowmelt processes explained in Section 1.1 were implemented.

Figure 5a shows the increase of SWI in the spring of 2006; however, such an increase is not found in Fig. 4a

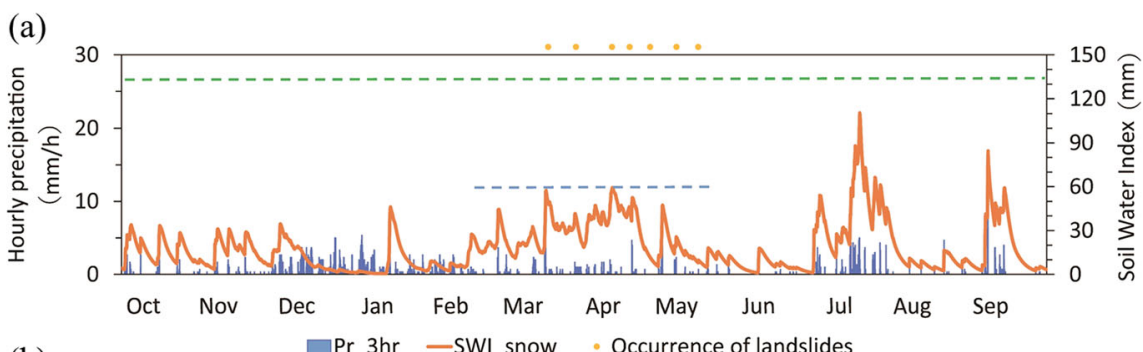

(b)

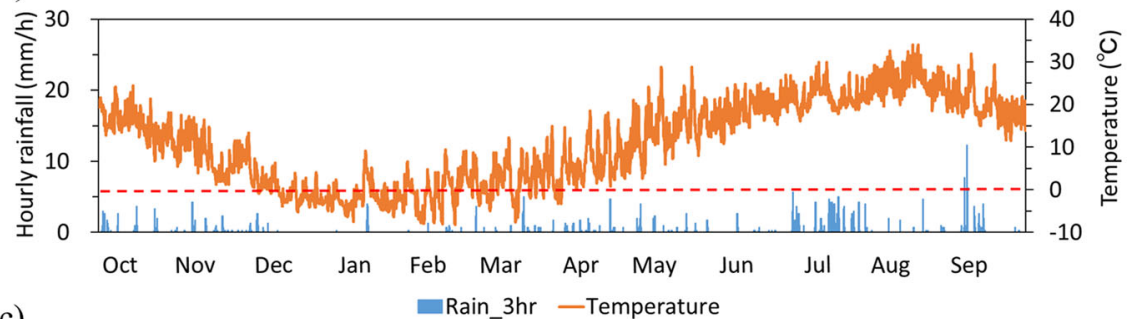

(c)
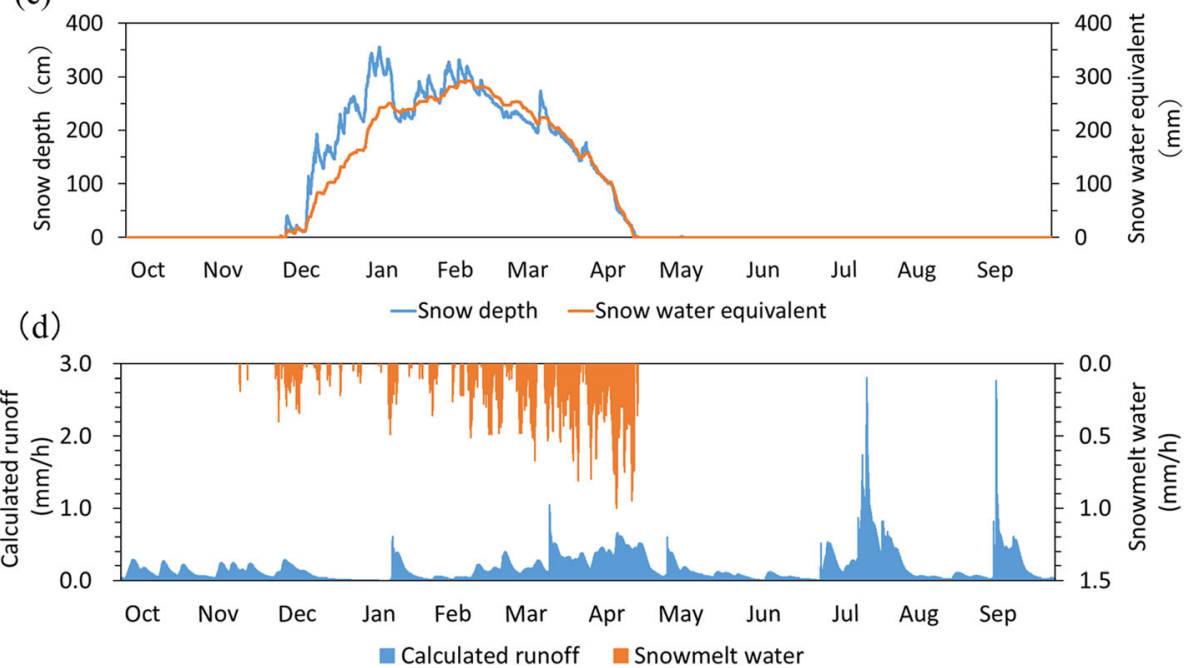

Fig. 5 a Same as Fig. 4b but modified SWI with considering snowfall-accumulation-snowmelt processes. The maximum SWI for March-May (57 $\mathrm{mm}$ ) of the past 10 years (1995-2004) is also plotted as blue dashed line. b Average of three-hourly rainfall and temperature at AMeDAS Sekiyama. The red dashed line represents $0^{\circ} \mathrm{C}$. c Observed snow depth (blue line) and calculated snow water equivalent (orange line) from October 1, 2005, to September 30, 2006, at AMeDAS Sekiyama. d Calculated runoff (blue bar) and snowmelt water (orange bar) from October 1 , 2005 to September 30, 2006 at AMeDAS Sekiyama. Note that the right axis is reversed 
and $\mathrm{b}$ because precipitation in the winter of 2005-2006 was snowfall that was later accumulated (Fig. 5c). Figure $5 \mathrm{~b}$ displays the time series of hourly rainfall and hourly temperature. As noted in the previous sentence, rainfall (not precipitation) was rarely observed from December to March because temperature during this period was below $2{ }^{\circ} \mathrm{C}$ in many cases.

SWI in Fig. $5 \mathrm{a}$ increased towards the end of the snowmelt season, and the maximum SWI in the snowmelt season $(59 \mathrm{~mm})$ appeared on April 12, 2006. The increase in SWI was in accordance with the occurrence of snowmelt-driven landslide disasters (yellow dots in Fig. 5a). The maximum SWI in Fig. 5a is $110 \mathrm{~mm}$ on July 19, 2006, which does not exceed the maximum SWI in the last 10 years ( $135 \mathrm{~mm}$, green dashed line).

Figure $5 \mathrm{c}$ depicts the observed snow depth (blue line, $\mathrm{cm}$ ) and calculated snow water equivalent (orange line, $\mathrm{mm}$ ) from October 1, 2005 to September 30, 2006, at AMeDAS Sekiyama (Fig. 2c). Note that these variables are different; however, if snow does not exist, both are 0 ( $\mathrm{cm}$ or $\mathrm{mm})$. In the snowmelt season, the maximum SWI $(59 \mathrm{~mm})$ on April 12 was larger than the maximum of the past 10 years from 1995 to $2004(57 \mathrm{~mm}$, blue dashed line in Fig. 5a). The yellow dots in Fig. 5a show that the landslide disasters concentrated after March 17, 2006, when SWI shows relatively larger values in the snowmelt season. Thus, predicting the occurrence of snowmelt-driven landslides is possible by focusing on the SWI in the snowmelt season alone.

Figure $5 \mathrm{~d}$ displays the time series of snowmelt water (Eq. 10) and the calculated runoff (sum of Eqs. 1, 2, and 3). Also, both scales are different. As the season progressed to the end of the snowmelt season, temperature was usually larger than $0{ }^{\circ} \mathrm{C}$ (Fig. 5b) which increased the snowmelt water (Eq. 10). The snowmelt water suddenly diminished to $0 \mathrm{~mm} / \mathrm{h}$ (Fig. 5d) when snow disappeared (Fig. 5c). As for the calculated runoff, it was relatively small value in comparison with the increase of SWI (Fig. 5a). Rather, larger runoff was observed in July and September when heavy precipitation was observed (Fig. 5a and b).

One question arises when we look at Fig. 5. In comparison with SWI in summer, snowmelt-driven landslide disasters occurred at a relatively smaller SWI (Fig. 5a). The burden of accumulated snow might physically affect the slope stability, and it may contribute to the occurrence of landslide disasters along with melting snow. However, we refrained from examining the dynamics of the snow movement because it is beyond the scope of this study.

\subsection{Application of modified SWI to meteorological data in Tomsk}

Based on the above results, we applied the modified SWI to the meteorological data in Tomsk from January
1999 to December 2010. We then investigated whether the calculated SWI and runoff could predict snowmeltdriven flood and landslide disasters in Tomsk city neighborhoods caused by sudden snow melting in the spring of 2010 (Fig. 3).

Figure 6a displays the estimated hourly precipitation (average of three-hourly precipitation) and SWI from October 1, 2009 to September 30, 2010 at Tomsk. The maximum SWI $(69 \mathrm{~mm})$ throughout the year in the past 10 years (1999-2008) is depicted as green dashed line, while that in the snowmelt season $(29 \mathrm{~mm})$ is displayed as blue dashed line. This figure shows that SWI on April 28, 2010 was the largest $(32 \mathrm{~mm})$, exceeding the maximum of the past 10 years in the snowmelt season. As portrayed in Fig. 3, April 28-30, 2010 was the mature stage of floods in that year. Around this time, landslides also occurred around Tomsk.

Figure $6 \mathrm{~b}$ is the time series of hourly rainfall and hourly temperature. We found that from November to March, temperature was mostly below $2{ }^{\circ} \mathrm{C}$. Reflecting this feature, rainfall was rarely observed from November to March as is like the case of Sekiyama (Fig. 5b). In contrast, snow began to accumulate from October (Fig. 6c). We also found that at the end of April, the snow water equivalent rapidly decreased. This feature is in accordance with the observed snow depth. Snowmelt water was also increasing from April to the beginning of May (Fig. 6d).

On May 1, the snow disappeared, and in turn, the calculated runoff showed the peak although it was relatively small value (Fig. 6d). It began to increase from April 26, and the maximum continued from April 29 to May 1 which may partly contribute to the severe floods (Fig. 3). The hydrological cycle in the snowmelt season was well reproduced by the modified SWI in that the decrease in the snow water equivalent was followed by the simultaneous increase in SWI, snowmelt water, and runoff.

Around the end of April, snowmelt-driven landslides occurred around Tomsk. Landslides near Tomsk are common along high and steep slopes of the Tom river valley and valleys of its tributaries. During floods, when the water level in rivers rises by several meters, the level of groundwater in the coastal zone rises as a result of backwater phenomena. The base of the slopes is weakening, the banks become less stable, and this is one of the main causes of landslides on the slopes of river valleys and, in particular, terraces. Melt and rainwater make an additional, and sometimes the main contribution to the recharge of groundwater flowing out at the base of the cliffs. Thus, landslides are usually caused due to complex factors in Tomsk.

We must consider that Fig. 6 is the result of point data, whereas the flood around Tomsk reflects the effect of the upper reach. Although the spatial scale is different 


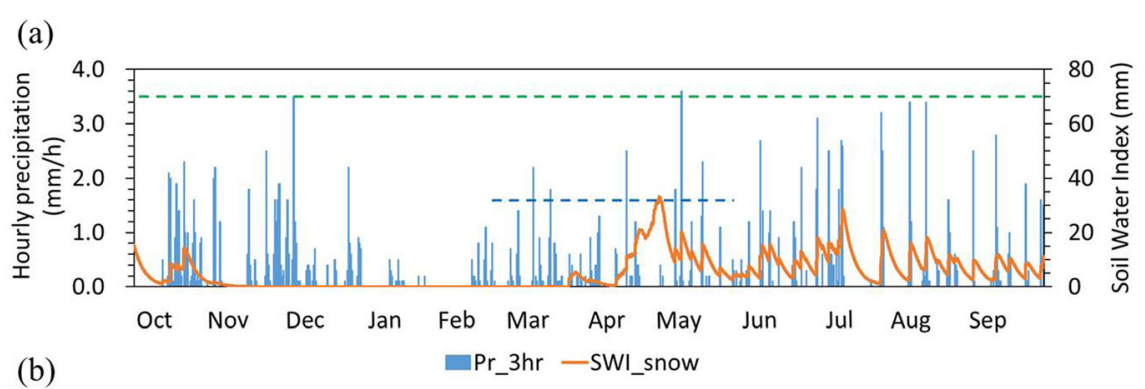

(b)

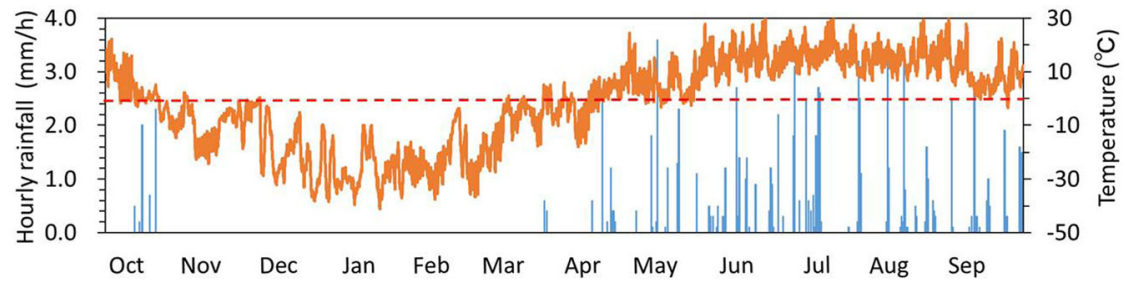

(c)

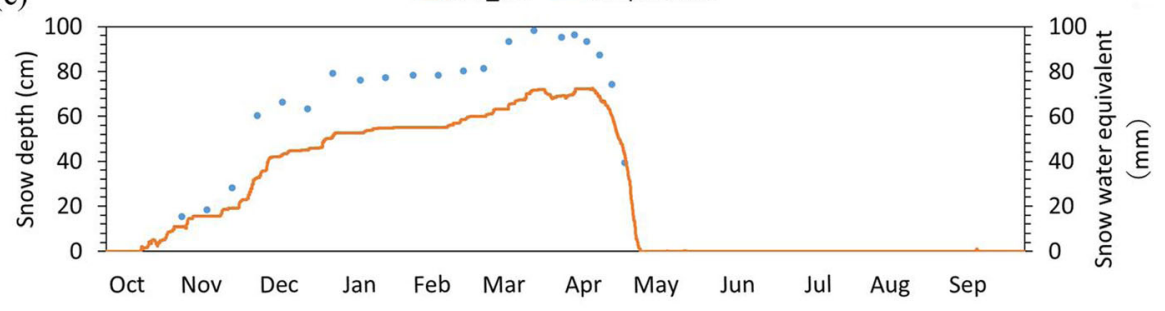

(d)

- Snow depth - Snow water equivalent

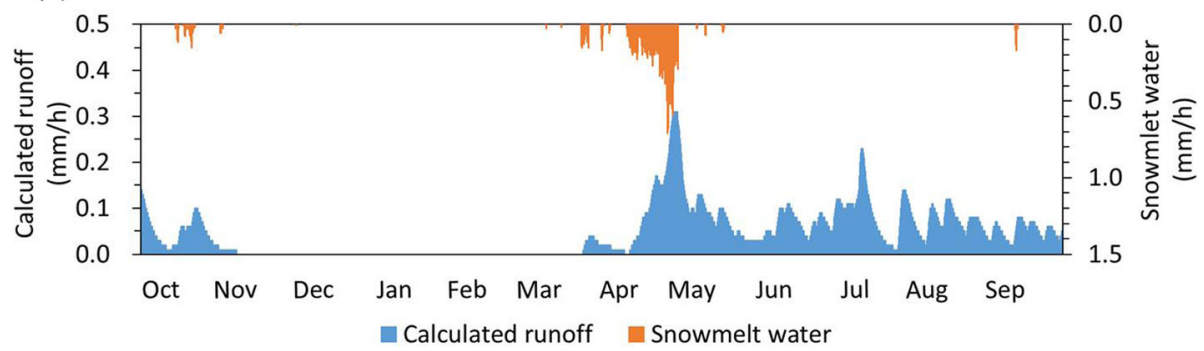

Fig. 6 Same as Fig. 5 but in Tomsk from October 1, 2009 to September 30, 2010. In a, the maximum SWI of the past 10years (1999-2008) throughout the year is $69 \mathrm{~mm}$, while that for March-May is $29 \mathrm{~mm}$

between Figs. 3 and 6, we think that local snowmelt also contributed to the flood situation in Fig. 3. In Tomsk, the snowmelt-driven flood and landslide disasters occurred when SWI in spring 2010 exceeded the maximum value of the snowmelt season. Namely, predicting the occurrence of snowmelt-driven flood and landslide disasters is possible by focusing on the SWI in the snowmelt season alone.

\section{Discussion}

\subsection{Relationship between snow depth and snow water equivalent, and the principle of SWI}

This study determined the snowmelt factor $\left(\mathrm{mm} \cdot{ }^{\circ} \mathrm{C} /\right.$ day $)$ by trial and error to match observed and calculated snow appearance/disappearance to implement snowfallaccumulation-snowmelt processes into the original SWI (Figs. 5 and 6). Although both snow depth and snow water equivalent have dimensions of length $[\mathrm{m}]$, they are different variables. When snow depth and snow density are given as $[\mathrm{cm}]$ and $\left[\mathrm{g} / \mathrm{cm}^{3}\right]$, respectively, the snow water equivalent $[\mathrm{mm}]$ is calculated using Eq. (11):

$$
\begin{aligned}
& \text { Snow water equivalent }[\mathrm{mm}]=\text { snow depth }[\mathrm{cm}] \\
& \times \text { snow density }[\mathrm{g} / \mathrm{cm} 3] \\
& \times 10[\mathrm{~cm} \rightarrow \mathrm{mm}]
\end{aligned}
$$

If the snow depth is $0 \mathrm{~cm}$, the snow water equivalent is also $0 \mathrm{~mm}$. Therefore, this study focused on the timing 
of snow appearance/disappearance because only snow depth data can be used to validate SWI. Both Figs. 5 and 6 reproduce the timing of snow appearance/disappearance well; however, quantitative problems are involved in the seasonal variations of snow depth and snow water equivalent.

The snow density of newly fallen snow is usually 0.10 $0.15 \mathrm{~g} / \mathrm{cm}^{3}$ and that of accumulated snow in spring is $0.5-0.6 \mathrm{~g} / \mathrm{cm}^{3}$ (Yamazaki 1994). According to the data of route snow surveys conducted by geographers of the National Research Tomsk State University at Luchanovo station, $20 \mathrm{~km}$ east of Tomsk, the snow density at the end of March 2010 was $0.21 \mathrm{~g} / \mathrm{cm}^{3}$ in the forested area and up to $0.27 \mathrm{~g} / \mathrm{cm}^{3}$ in the field (Petrov et al. 2013). Figure $6 \mathrm{c}$ depicts the seasonal variation of the observed snow depth and calculated snow water equivalent at Tomsk from 2009 to 2010. From this figure, we found that the snow depth was $100 \mathrm{~cm}$ at the end of March 2010, just before the beginning of snowmelt. Here, if we assume a snow density of $0.24 \mathrm{~g} / \mathrm{cm}^{3}$, the snow water equivalent calculated by Eq. (10) was $240 \mathrm{~mm}$. However, the snow water equivalent displayed in Fig. $6 \mathrm{c}$ is only 70 $\mathrm{mm}$. The seasonal variation of the snow water equivalent is qualitatively well reproduced by the modified SWI; however, it has quantitative uncertainties, as discussed here.

In this regard, previous studies (Usutani et al. 2013; Nakatsugawa et al. 2015; Miyazaki et al. 2017) used river discharge data of the study area to validate snow water equivalent investigating snowmelt-driven landslide disasters using the tank model. Usutani et al. (2013) optimized the parameters of the tank model for their study area, so that, transferring the parameters to other basins is difficult.

In principle, SWI can be calculated all over the world with the three-layer tank model by including geologic parameters involving an abundance of granite (Fig. 1, Ishihara and Kobatake 1979). In Ishihara and Kobatake (1979), the three-layer tank model has five kinds of parameters depending on the geologic types; that is, SWIs of each type are different. However, the relative ranks of SWI are consistent even when the parameters are changed (Okada et al. 2001). This is a merit of SWI, such that even with quantitative problems involved in Figs. 5 and 6, we can predict snowmelt-driven landslide disasters by focusing on the ranks of SWI in the snowmelt season.

\subsection{Meteorological data for Tomsk}

Meteorological data for Tomsk (RIHMI-WDC 2020) presents some problems. As for snow depth, we cannot determine the snow disappearance period in some years in which April 2010 was involved (Fig. 6c). Figure 6c shows that the snow depth was $39 \mathrm{~cm}$ on April 25, 2010, which was the final observation of that season. We have already noted that the snowmelt factor was determined by matching the appearance/disappearance of the observed snow depth and calculated snow water equivalent; however, the observed snow depth can encounter the aforementioned problem. The snowmelt factor $\left(0.7 \mathrm{~mm} \cdot{ }^{\circ} \mathrm{C} /\right.$ day $)$ estimated by trial and error has quantitative uncertainties, as explained here.

In Tomsk, we used three-hourly meteorological data from January 1999 to December 2010. Because the snow depth data used for the validation has such problems, it is important to measure snow depth from winter to spring to accurately predict snowmelt-driven landslide and flood disasters. It is especially important to capture the snow disappearance date for the validation of the present study.

\subsection{Transferability of the snowmelt factor in Tomsk for analyses of other years}

After estimating the snowmelt factor in Tomsk (0.7 $\mathrm{mm} \cdot{ }^{\circ} \mathrm{C} /$ day), the next aspect to consider is its transferability for the analyses of other years.

Figure 7 shows seasonal variations of observed snow depth and calculated snow water equivalent from 1999 to 2000 (first years of the past 10 years which SWI during 2009-2010 refers to) and those from 2006 to 2007 (last years of the past 10 years when observed snow depth is available) in Tomsk. In these years, the appearance/disappearance of snow is well simulated, although observation stopped at the end of April. However, visual inspection of Fig. 7 enables the transferability of the snowmelt factor $(0.7$ $\mathrm{mm} \cdot{ }^{\circ} \mathrm{C} /$ day) estimated in $2009-2010$ for the analyses of other years.

Although figures were not included, we carried out similar analyses from 2000 to 2006, apart from the years of 1999-2000 and 2006-2007, and obtained satisfactory results. We can set the snowmelt factor at Tomsk to 0.7 $\mathrm{mm} \cdot{ }^{\circ} \mathrm{C} /$ day regardless of the years. Additionally, the discussion in the previous section mentions the importance of measuring snow depth and temperature in spring to accurately predict snowmelt-driven landslide and flood disasters.

\section{Conclusions}

The novel findings of this study are summarized as follows:

1) We demonstrated how SWI changed if we estimated hourly precipitation from the average of three-hourly accumulated precipitation. We selected the Sekiyama region in Niigata Prefecture, Japan, which is characterized by 


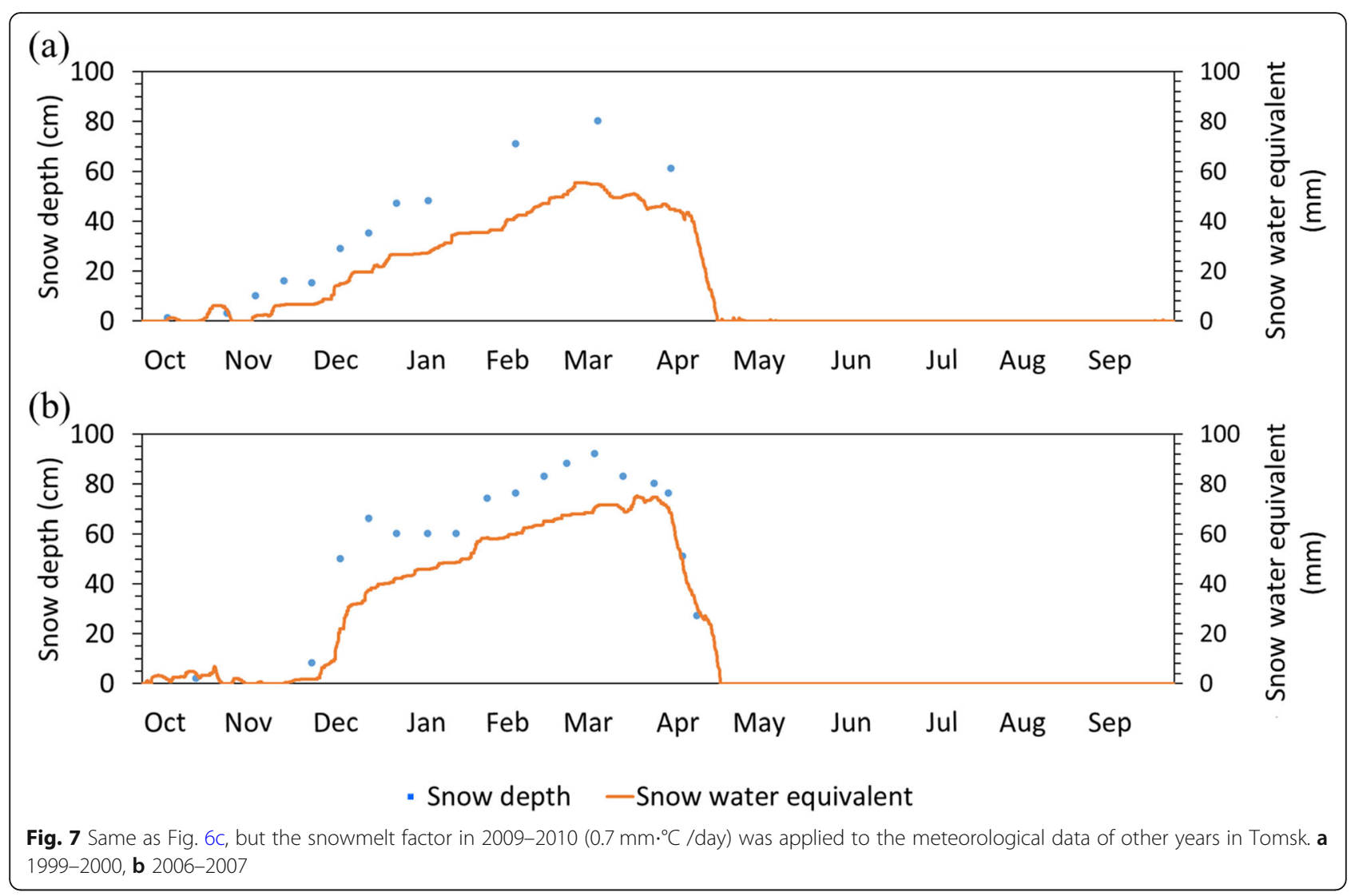

frequent snowmelt-driven landslide disasters. When we input the average of the three-hourly accumulated precipitation to calculate SWI, the result was almost identical to one when the observed hourly precipitation was used for the calculation.

2) We implemented snowfall-accumulationsnowmelt processes into the original SWI. Around the Sekiyama region from October 2005 to September 2006, the modified SWI accurately represented snowfall-accumulation-snowmelt processes and predicted the occurrences of landslide disasters in snowy regions in the snowmelt season (March-May).

3) We applied the modified SWI to meteorological data in Tomsk to evaluate the validity of the calculation in the spring of 2010 when severe snowmelt-driven flood and landslide disasters occurred. SWI and calculated runoff accurately captured the timing of snowmelt-driven flood and landslide disasters in spring 2010. We also demonstrated that by focusing on the maximum value of SWI in the snowmelt season for the past 10 years, we can predict snowmelt-driven landslide disasters.
Furthermore, we discussed the quantitative relationship between snow depth and snow water equivalent, the merit of SWI, the problems involved in the meteorological data in Tomsk, and the transferability of snowmelt factor in Tomsk for the analyses of other years.

\section{Abbreviations}

AMeDAS: Automated Meteorological Data Acquisition System operated by Japan Meteorological Agency; RIHMI-WDC: All-Russia Research Institute of Hydrometeorological Information-World Data Center; SWI: Soil Water Index

\footnotetext{
Acknowledgements

We are grateful to Professors S. Kirpotin and V. Khromykh of National Research Tomsk State University for their guidance throughout this study. Critical comments by anonymous reviewers and the editor are valuable for improving the original manuscript. Personal communication with Mr. K. Okada of Japan Meteorological Agency is highly appreciated. This study was supported by WNI WxBunka Foundation, JSPS KAKENHI (18KK002800), and JST/SICORP Grant Number JPMJSC1901, Japan. VZ is also supported by the Russian Federal Targeted Program Grant RFMEFI61419X0002.
}

\section{Authors' contributions}

HM proposed the topic, and conceived and designed the study. He also analyzed the hydrometeorological data. HS collected the data of landslide disasters in Japan. VZ collected the data of snowmelt-driven flood and landslide disasters in Russia. HS and VZ helped in the interpretation of the results and collaborated with $\mathrm{HM}$ in the preparation of the manuscript. All authors read and approved the final manuscript. 


\section{Funding}

This study was supported by WNI WxBunka Foundation, JSPS KAKENHI (18KK002800), and JST/SICORP Grant Number JPMJSC1901, Japan. VZ is also supported by the Russian Federal Targeted Program Grant RFME Fl61419X0002.

\section{Availability of data and materials}

The datasets supporting the conclusions of this article are available in Japan Meteorological Agency (2020) and RIHMI-WDC (2020). Other data are available from the authors on request.

\section{Competing interests}

The authors declare that they have no competing interests.

\section{Author details}

1Department of Geography, Tokyo Metropolitan University, 1-1 Minami-Osawa, Hachioji, Tokyo 192-0397, Japan. ${ }^{2}$ College of Economics, Kanto Gakuin University, 1-50-1 Mutsuura-Higashi, Kanazawa-ku, Yokohama, Kanagawa 236-8501, Japan. ${ }^{3}$ Department of Hydrology, National Research Tomsk State University, 36, Lenina Pr., Tomsk 634050, Russia.

\section{Received: 21 September 2020 Accepted: 13 January 2021}

\section{Published online: 12 February 2021}

\section{References}

Chen CW, Saito H, Oguchi T (2017) Analyzing rainfall-induced mass movements in Taiwan using the Soil Water Index. Landslides 14:1031-1041 https://doi. org/10.1007/s10346-016-0788-1

Cruden D, Varnes D (1996) Landslide types and process. In: Turner KA and Schuster RL (eds) Landslides: investigation and mitigation. U.S. National Research Council Transportation Research Board Special Report 247: 36-75

Guzzetti F, Peruccacci S, Rossi M, Stark CP (2008) The rainfall intensity-duration control of shallow landslides and debris flows: an update. Landslides 5:3-17 https://doi.org/10.1007/s10346-007-0112-1

Ishihara Y, Kobatake S (1979) Runoff model for flood forecasting. Bulletin of Disaster Prevention Research Institute, Kyoto University 29: 27-43

Japan Meteorological Agency (2020) Past meteorological data for downloading https://www.data.jma.go.jp/gmd/risk/obsdl/index.php. (in Japanese) Accessed 5 Jan 2020

Kimura T, Hatada K, Maruyama K, Noro T. (2014). A probabilistic approach to predicting landslide runout based on an inventory of snowmelt-induced landslide disasters in Japan. International Journal of Erosion Control Engineering 7: 9-18. https://doi.org/10.13101/ijece.7.9

Miyazaki T, Nakatsugawa M, Usutani T (2017) Risk evaluation of landslide disaster occurrence using quantification of soil moisture considering snowmelt. Journal of Japan Society of Hydrology and Water Resources 30: 89-101. https://doi.org/10.3178/jjshwr.30.89 (in Japanese with English abstract)

Motoyama H (1990) Simulation of seasonal snowcover based on air temperature and precipitation. Journal of Applied Meteorology 29: 1104-1110. https://doi. org/10.1175/1520-0450(1990)029<1104:SOSSBO>2.0.CO;2

Nakatsugawa M, Usutani T, Miyazaki T (2015) Risk assessment of sediment disaster based on watershed-wide hydrological processes. E-proceedings of the 36th IAHR World Congress. https://www.iahr.org

Ogawa M, Nogami M (1994) Precipitation amount separated by precipitation type using discriminating temperature during winter season. Journal of Japan Society of Hydrology and Water Resources 7: 421-427. https://doi.org/ 10.3178/jjshwr.7.421 (in Japanese with English abstract)

Ohno H, Yokoyama K, Kominami Y, Inoue S, Takami S, Wiesinger T (1998) Catch ratios of gauges for solid precipitation in Hokuriku region. Seppyo 60: 225231. https://doi.org/10.5331/seppyo.60.225 (in Japanese with English abstract)

Ohta T, Makihara Y (2019) Technical developments for mitigating disasters from inundation and flood and dissemination of their results. Tenki 66:723-742 (in Japanese)

Okada K (2007) Current state of disaster generation risk forecast by Soil Water Index. Tsuchi-to-kiso 55(9):4-6 (in Japanese)

Okada K, Makihara Y, Shimpo A, Nagata K, Kunitsugu M, Saito K (2001) Soil Water Index. Tenki 48:349-356 (in Japanese)

Osanai N, Shimizu T, Kuramoto K, Kojima S, Noro T (2010) Japanese earlywarning for debris flows and slope failures using rainfall indices with radial basis function network. Landslides 7: 325-338. https:// doi.org/10.1 007/s10346-010-0229-5

Petrov A, Yevseyeva N, Kashiro M (2013) Dynamics of snow cover characteristics in landscapes of the Tom-Yaya interfluve. Bulletin of Tomsk State University 371:183-188 (in Russian with English abstract)

RIHMI-WDC (2020) Weather over the territory of the Russian Federation in 2010. http://meteo.ru.

Saito H, Matsuyama H (2012) Catastrophic landslide disasters triggered by recordbreaking rainfall in Japan: their accurate detection with Normalized Soil Water Index in the Kii Peninsula for the year 2011. SOLA 8:81-84 https://doi. org/10.2151/sola.2012-021

Saito H, Matsuyama H (2015) Probable hourly precipitation and Soil Water Index for 50-yr recurrence interval over the Japanese archipelago. SOLA 11:118-123 https://doi.org/10.2151/sola.2015-028

Saito H, Nakayama D, Izumi T, Matsuyama H (2011) Real-time monitoring of rainfalls associated with shallow landslides-development and verification of SWING system based on two rainfall patterns-. Theory and Applications of GIS 19(2): 25-34. https://doi.org/https://doi.org/10.5638/thagis.19.81 (in Japanese with English abstract)

Saito H, Nakayama D, Matsuyama H (2010a) Relationship between the initiation of a shallow landslide and rainfall intensity-duration threshold in Japan. Geomorphology 118:167-175 https://doi.org/10.1016/jgeomorph.2009.12.016

Saito H, Nakayama D, Matsuyama H (2010b) Two types of rainfall conditions associated with shallow landslide initiation in Japan as revealed by Normalized Soil Water Index. SOLA 6:57-60 https://doi.org/10.2151/sola. 2010-015

Sekine T, Katsura S (2020) Study on the hydrological measure that best correlates with the daily landslide displacements. Journal of the Japan Landslide Society 57(2):19-26. https://doi.org/10.3313/jls.57.59 (in Japanese)

Shimizu A, Uemura T (2018) Estimation of recharge area for spring water by use of radar-raingauge analyzed precipitation-a case study at Otomeyama Park, Shinjuku Ward, Tokyo Metropolis. Journal of Japanese Association of Hydrological Sciences 48: 3-16. https://doi.org/10.4145/jahs.48.3 (in Japanese with English abstract)

Siva Subramanian S, Ishikawa T, Tokoro T (2018) An early warning criterion for the prediction of snowmelt-induced soil slope failures in seasonally cold regions. Soils and Foundations 58:582-601 https://doi.org/10.1016/j.sandf. 2018.02.021

Tanaka T, Ohta T, Makihara Y (2008) Flood warning/advisory improvement based on JMA Runoff Index. Weather Service Bulletin 75(2):35-69 (in Japanese)

Territorial Center "Tomskgeomonitoring" (2020) Tomsk. https://www.tgm.ru/ Accessed 5 Jan 2020

Usutani T, Nakatsugawa M, Matsuoka N (2013) Quantitative evaluation of soil moisture associated with landslide disasters during snowmelt period. Journal of Japan Society of Civil Engineering B1 (Hydraulic Engineering) 69: I_403-I_408. https://doi.org/10.2208/jscejhe.69.I_403 (in Japanese with English abstract)

Yamazaki T (1994) Snow and atmosphere. In: Kondo J (ed) Meteorology in water environment. Asakura Publishing Co. Ltd.: 240-260 (in Japanese)

\section{Publisher's Note}

Springer Nature remains neutral with regard to jurisdictional claims in published maps and institutional affiliations. 